\title{
Effect of light on the Lactobacillus casei microbiological assay
}

\author{
BARBARA B. ANDERSON ${ }^{1}$ AND JEAN D. COWAN ${ }^{1}$ \\ From the Medical Research Council Group for Investigation of Megaloblastic and Sideroblastic \\ Anaemias, Postgraduate Medical School, London
}

SYNOPSIS Because of the considerable differences in the reported values for serum folate in normal subjects using Lactobacillus casei as assay organism the effect of daylight when preparing media for this assay was studied. It was found that the growth properties of the medium were destroyed by direct sunlight and impaired by bright reflected sunlight, therefore reducing the sensitivity of the assay. Adequate precautions regarding exposure to light must be taken.

There are considerable differences in the reported values of the serum folate concentration in normal subjects using Lactobacillus casei as assay organism; the mean concentration in 17 different laboratories ranges from 4.6 to $15.8 \mathrm{~m} \mu \mathrm{g}$. $/ \mathrm{ml}$. (Mollin and Hoffbrand, 1965). Growth of the organism in the folic acid (pteroylglutamic acid) standards often differs widely from one laboratory to another and even from one batch to the next in the same laboratory.

Some of the factors which can contribute to these variations have been summarized by Mollin and Hoffbrand (1965). Recently it was noticed that when assays were set up on a bright day there was poor growth of $L$. case $i$. The purpose of this paper is to analyse the effect of light on the $L$. case $i$ assay by studying (1) the effect of light on the assay medium; (2) the effect of light on the standard folic acid solutions and serum folate extracts; and (3) whether exposing the assay medium to light alters the value obtained for the serum folate concentration. Studies on this subject have not been published previously, but Hansen (1964) suggested that the assay medium for $L$. casei should be protected from light.

\section{MATERIALS AND METHODS}

In these experiments the organism used was Lactobacillus casei (A.T.C.C. 7469) which is the organism generally used for the assay of serum folate. The method used was that of Waters and Mollin (1961) but the medium was the dry-mix, Bacto-Folic Acid Casei Medium, Difco No. 0822. In order to prepare the medium, an appropriate amount was dissolved in distilled water, brought to the boil, boiled for three minutes and cooled.

'Present address: Department of Haematology, St. Bartholomew's Hospital, London, E.C.1.

Received for publication 24 May 1967.

\section{RESULTS}

EFFECT OF LIGHT ON THE ASSAY MEDIUM Batches of the Difco medium were exposed to light of different intensities during and after preparation, as follows: (1) medium boiled and kept in subdued light throughout ('medium I'); (2) medium boiled in bright reflected sunlight and then kept in same for two hours ('medium II'); (3) medium boiled in the

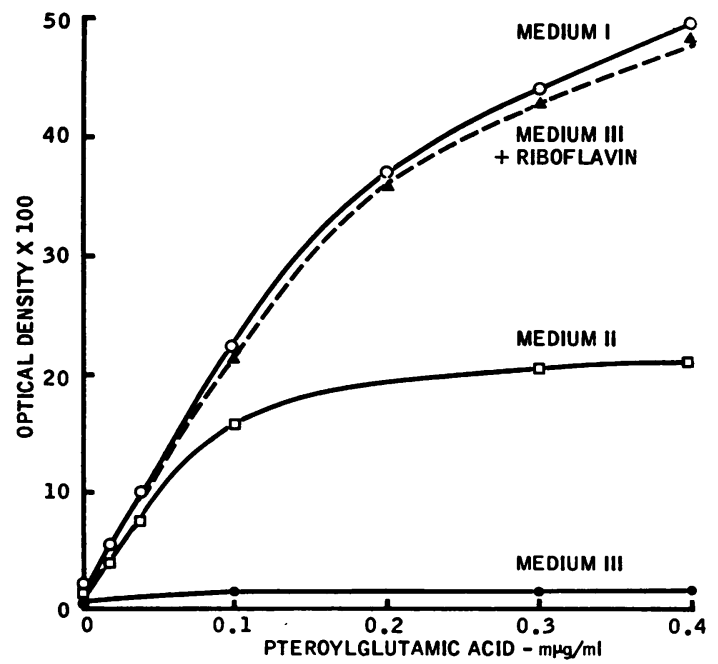

FIG. 1. Effect of light on the L. casei medium. Medium I was boiled and kept in subdued light throughout. Medium II was boiled in bright reflected sunlight and kept in same for two hours. Medium III was boiled in the presence of sunlight and kept in bright reflected sunlight for two hours. 
presence of sunlight and kept in bright reflected sunlight for two hours ('medium III').

Growth of $L$. case $i$ in folic acid standards is compared in these three media in Figure 1. The most growth occurred in medium I which had been protected from exposure to light. There was no growth in medium III (exposed to direct sunlight), and in medium II (exposed to reflected sunlight) there was some growth but considerably less than in medium I.

As riboflavin is known to be rapidly destroyed by light, the appropriate amount was added to a portion of medium III. Growth in folic acid standards was then almost the same but not quite as much as in medium I (Fig. 1). When $B_{6}$ (pyridoxine), which is also sensitive to light, was added as well as riboflavin, growth was the same as in medium I. The addition of $\mathbf{B}_{6}$ alone to medium III without riboflavin did not increase growth of $L$. casei in the defective medium. It appears that whereas riboflavin is rapidly and completely destroyed by short exposure to sunlight, $B_{6}$ is only partially destroyed. Addition of riboflavin to medium II completely restored its growth properties for $L$. casei, suggesting that enough $B_{6}$ remained in the medium under these conditions to allow full growth if riboflavin was added.

As might be expected when $L$. casei was used to assay pyridoxal in serum, light had the same effect on the assay medium. The medium used in these experiments was prepared in the laboratory according to the method of Waters and Mollin (1961) but with folic acid replacing $B_{6}$.

EFFECT OF LIGHT ON STANDARD FOLIC ACID SOLUTIONS AND SERUM FOLATE EXTRACTS Exposure to bright reflected sunlight for three hours had no significant effect on the folate content of the standard solutions and serum extracts. Growth of the organism was the same in standards and serum extracts which had been kept in subdued light as in those exposed to bright reflected light for periods up to three hours.

On the other hand, as expected, exposure to direct sunlight caused reduced growth of $L$. case $i$ both in the standards and serum extracts, presumably due to destruction of folate.

EFFECT ON SERUM FOLATE ASSAY VALUES OF EXPOSURE OF MEDIUM TO BRIGHT REFLECTED SUNLIGHT In Fig. 2 the serum folate values obtained using medium exposed to bright reflected sunlight (medium II) are plotted against the values obtained using medium protected from light (medium I). For serum folate concentrations up to $8 \mathrm{~m} \mu \mathrm{g}$. $/ \mathrm{ml}$. the values obtained were approximately similar, but at higher concentrations the values using medium prepared in

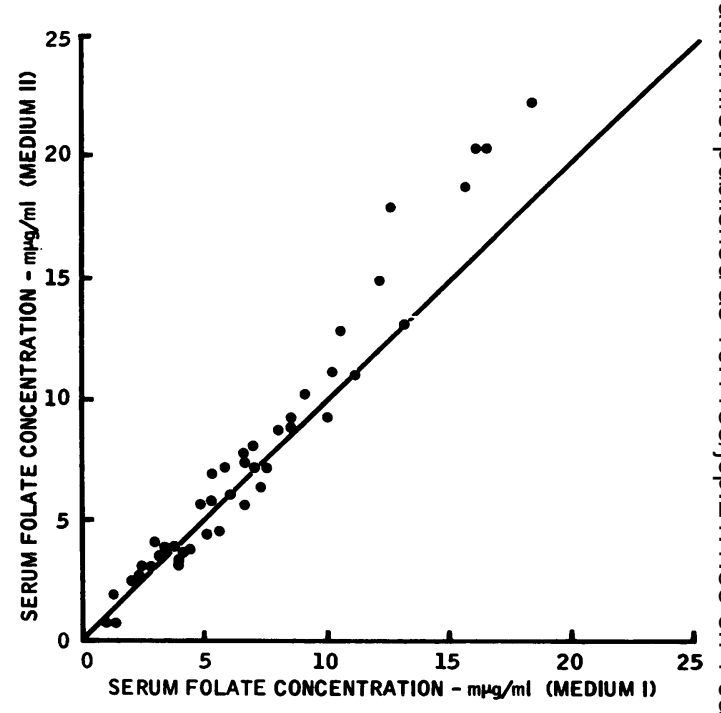

FIG. 2. The relationship between the serum folate concentrations obtained using medium I and medium II.

bright reflected sunlight were on the whole considerably higher.

This could be explained by assuming that serum itself contains riboflavin. The effect of the deficiency of riboflavin in the medium would be most obvious in sera with high folate concentrations because there $\mathbb{\perp}$ is greater growth of $L$. casei. The diminished amount $\underset{\vec{F}}{\overrightarrow{7}}$ of riboflavin in the medium becomes a limiting factor for the standards and the serum folate values are consequently falsely high. This same effect was observed in sera with higher pyridoxal concentrations when using $L$. case $i$ to assay serum pyridoxal.

\section{CONCLUSION}

Medium exposed to direct sunlight supports no growth of the assay organism because of the destruc- 윽 tion of riboflavin and to some extent other light- $>$ sensitive vitamins. Bright reflected sunlight also affects the growth properties of the medium for the same reason but to a lesser degree. However, the effect on the actual assay values using this defective $\tilde{O}$ medium is negligible for serum folate concentrations up to $8 \mathrm{~m} \mu \mathrm{g}$. $/ \mathrm{ml}$., which is the range of greatest 0 diagnostic importance. Therefore it can only con- 0 tribute in a small way to the variations found in this $\underset{\mathbb{D}}{\stackrel{C}{2}}$ range in different laboratories. But for sera with $\stackrel{\oplus}{?}$ higher folate concentrations the values are falsely 0 high using a defective medium. When a high control 0 serum is used to standardize the assay method in $\frac{\mathbb{}}{\circ}$ different parts of the world where light intensity can $\mathbb{\mathbb { D }}$ be widely different, the values obtained are likely to $\frac{2}{2}$ 
vary considerably, if adequate precautions regarding exposure to light are not taken.

In order to obtain the most accurate and reproducible assay it is essential to prepare the medium in subdued light and to protect it from bright light throughout the assay procedure. Although there is no direct evidence that bright reflected light affects folate in standard solutions and serum extracts for periods of exposure of up to three hours, it would seem reasonable to protect these from light also.

\section{REFERENCES}

Hansen, H. A. (1964). On the Diagnosis of Folic Acid Deficiency, p. 34. Almqvist and Wiksell, Stockholm.

Mollin, D. L., and Hoff brand, A. V. (1965). The diagnosis of folate deficiency. In Vitamin $B_{12}$ and Folic Acid (Scand. J. Haemat., Series Haematologica, 3), p. 1. Munksgaard, Copenhagen.

Waters, A. H., and Mollin, D. L. (1961). J. clin. Path., 14, 335. 